За допомогою диференційних рівнянь стану системи описано розрахунки перехідни і установлених режимів роботи імпульсних перетворювачів. Ці розрахунки у матричній формі розділяються на електромагнітну $i$ теплову складові. Рішення таких диференційних рівнянь аналізуються з точки зору забезпечення теплового захисту перетворювача без додавання пристроїв теплового захисту. Отримано рішення електротеплових рівнянь системи, за допомогою якого можна підбором матеріалів пасивних компонентів та вибору активних компонентів із певними граничними значеннями уникнути теплових аварій перетворювача

Ключові слова: рівняння стану системи, тепловий імпеданс, матрична експонента, електротеплове моделювання

С помощью дифференциальных уравнений состояния системы описаны расчёты переходных и установившихся режимов работы импульсных преобразователей. Данные расчёты в матричной форме разделяются на электромагнитную и тепловую составляюшие. Решения данных дифференциальных уравнений анализируются с точки зрения установления тепловой защиты преобразователя без добавления устройств тепловой защиты. Получено решение электротепловых уравнений системы, с помощью которого можно подбором материалов пассивных элементов и выбором активных элементов с определенными граничными значениями избежать тепловых аварий преобразователя

Ключевые слова: уравнения состояния системы, тепловой импеданс, матричная әкспонента, әлектротепловое моделирование
UDC 621.314

DOI: $10.15587 / 1729-4061.2016 .73541$

\title{
CALCULATION OF ELECTROTHERMAL PROCESSES IN PULSE CONVERTERS TO PROVIDE THERMAL PROTECTION
}

\author{
R. B a ra ni u k \\ Postgraduate student* \\ E-mail: licornedev@gmail.com \\ V. Todore n k o \\ $\mathrm{PhD}$, Associate Professor* \\ E-mail: ikar@fel.ntu-kpi.kiev.ua \\ D. Ush akov \\ Postgraduate student* \\ E-mail: dushakov@ua.fm \\ *Department of industrial electronic \\ "Kyiv Polytechnic Institute"
} National Technical University of Ukraine

Peremohy ave., 37, Kyiv, Ukraine, 03056

\section{Introduction}

Nowadays, one of the most urgent problems of power electronics is to minimize the size and to optimize power supply for semiconductor converters. As a result of downsizing, electronic components are becoming more sensitive to external influences, current surges, and thermal stresses. Due to an increase in thermal capacity, heat transfer during fast processes becomes complicated.

According to previous research [1], almost $60 \%$ of accidents occur as a result of semiconductor converters overheating. In this case, every $10{ }^{\circ} \mathrm{C}$ increase in temperature doubles the accident rate.

In order to ensure trouble-free operation of a converter, it is necessary to stabilize the thermal conditions. This can be done with the help of methodological and circuit approaches. The methodological approach is a simulation of thermal processes and the selection of the converter component parameters so that, even with a decrease in the maximum permissible parameters of the device components due to the heat during the restart and the occurrence of transients, these parameters are not exceeded. Moreover, magnetic materials and elements of the device can be chosen so that the simultaneous heating of several elements can result in a mutual compensation of the influence of changes in the electrical parameters of the heated components on the output characteristics of the circuit or device. The circuit design approach involves introduction of additional devices or chains in the circuit with a view to respond to the emergency sections of the device.

Creation of thermal protection of converting devices is complicated by the fact that using power switches due to the thermal capacity makes it impossible to perform a full removal of heat from the semiconductor device chip. Especially dangerous are the reclosing modes in which the heated appliance with lowered boundary values gets a thermal stress. These processes must be modelled by solving the problem in a methodological way, calculating the electrothermal processes that are combined in the device and selecting the elements of the circuit so as to reduce the amount of thermal stress and soften the character of the transition process when the heated converter is switched on.

\section{Analysis of the published studies and} formulation of the problem

To create thermal protection, it is necessary to analyse the combined electromagnetic and thermal processes of the 
converter. In [2], it is suggested to use a thermal model of an IGBT transistor, which is based on solving equations on thermal conductivity. The thermal models expressed through 1D and 2D Fourier series were programmed in MATLAB/Simulink. Besides, an analysis is performed for a transistor having a power diode and a heat sensor under inductive load. This model does not help conduct accurate analysis, and the estimates that are based on the temperature stresses in the transistor chip will not be relevant because of the required computation time. In [3], eddy currents are calculated, and the electromagnetic field is analysed in conjunction with the thermal field on heating the cylindrical rod of the inductive element. These methods are well suited for a thermal simulation and thermal protection in a steady operation mode of the converter. The major drawback of these methods is that they cannot help calculate the thermal shocks in the crystal of semiconductor devices at switching them on, especially in an intermittent mode.

For accurate modelling of transitional processes, it is necessary to separate the electric and thermal components of the model, since a joint calculation of short-term electromagnetic processes and long-term thermal processes will accumulate a modelling error. In study [4], it is suggested to derive the thermal model from the finite elements of model simulation. This method is used to develop an electric simulator that is able to use a thermal model [5]. However, in these two sources there is no feedback from the thermal model to the electric power model, though the need for it is stated as a problem to solve.

Study [6] aims at providing a compact equivalent RC-chain to predict the time dependence of cooling the device with a passive heat sink. There is an analysis of thermal conductivity depending on the input power. Besides, there is a consideration of how an error in thermal modelling depends on the degree of approximation. The described study could be used to provide thermal protection by regulating the input power of the converter's nonlinear circuit.

The problem of thermal protection at a recloser can be most probably solved by analysing thermal stresses in crystals of semiconductor devices as described in [7]. Electrothermal processes in a quasi-dynamic model of a MOS-transistor are studied at changing the basic characteristics under increased temperature. The example shows that it is difficult to apply a capacitive load due to an excessive chip temperature at switching on. Thermal processes of transistors at different connections within an equivalent circuit of thermal displacement on the basis of Infineon transistors are analysed in detail in [8]. These are significant studies by Infineon, a manufacturer of semiconductor devices and power modules.

The problem of electrothermal modelling and establishing thermal protection of converters is quite important. One of the most comprehensive studies in this area was carried out by the Eindhoven University of Technology [9] on the basis of publications and studies of recent decades. Research in this area still needs improving.

The methods of electrothermal simulation that can be used in recurrent short-term modes of pulse converters do not take into account many factors, such as changing the temperature dependence of magnetic materials due to changes in the circuit current, the thermal field of the device, etc. Consequently, it is useful to develop a method of calculating electric processes to provide thermal protection of pulse converters the use of which is possible both in steady and intermittent modes of the device operation.

\section{The purpose and tasks of the study}

The purpose is to calculate the electrothermal processes of a converter so that the models of electromagnetic and thermal processes or the control system during operation could prevent an emergency mode of the device caused by overheating at the design stage.

To achieve this purpose, it is necessary to do the following tasks:

- to develop and solve differential equations on the system state for electromagnetic processes in a matrix form, which are expanded by adding the thermal component;

- to analyse the matrix exponentials that characterize the transition process as well as to determine the parameters by adjusting which it is possible to reduce oscillation during the transition process in the moments that are close to overheating or an accident;

- to select the maximum parameter values of elements in the desired temperature range, to choose the inductor core with the necessary dependencies of the magnetic permeability on the temperature and the magnetic field strength, and to calculate, if necessary, additional chains of protection against overheating.

\section{A thermal simulation of pulse converters}

\section{1. Thermal models of the device components}

It is necessary to measure the parameters of the converter components at the required operating frequency range and to determine the analytical dependence of the component parameters on the temperature deviation from the normal value.

The research concerns the circuit of a step-down pulsewidth modulator (PWM) of the 2nd order shown in Fig. 1.

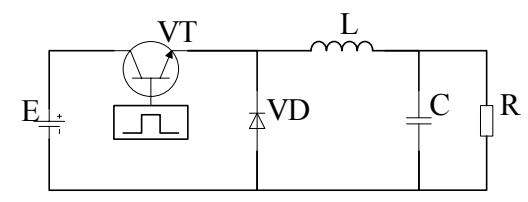

Fig. 1. The circuit of a step-down PWM converter

The circuit elements:

- VT is a MOSFET transistor IRFP4232;

- VD is a diode D650N;

- L is an inductor with a core $3 \mathrm{~S} 11$ by Philips [10];

- C is a capacitor Epcos B43415 [11].

When the mechanism is switched on or at intermittent modes of operation, its semiconductor devices are at the forefront. During the fast processes of switching on, the temperature of the semiconductor device crystal can greatly exceed the device body temperature. Fig. 4 shows a thermal transition process when applying a pulse current to the transistor VT at the housing and heat sink temperature amounting to $50{ }^{\circ} \mathrm{C}$ [7].

The heat capacity depends on the composition of the semiconductor material between the crystal and the housing as well as their splicing. The heating of the crystal is calculated as:

$$
\mathrm{T}_{\mathrm{j}}(\mathrm{t})=\mathrm{T}_{\mathrm{c}}(\mathrm{t})+\mathrm{P}(\mathrm{t}) \cdot \sum_{\mathrm{i}=1}^{\mathrm{n}} \mathrm{R}_{\mathrm{th} . \mathrm{i}}\left(1-\mathrm{e}^{\frac{-\mathrm{t}}{\mathrm{C}_{\mathrm{th} . \mathrm{R}} \mathrm{R}_{\mathrm{th} . \mathrm{i}}}}\right),
$$


where $\mathrm{T}_{\mathrm{c}}$ is the body temperature, $\mathrm{P}$ is the instantaneous power, $\mathrm{R}_{\text {th }}$ and $\mathrm{C}_{\text {th }}$ are thermal resistance and capacitance. The expression under the sum operator is the thermal impedance between the crystal and the case of the semiconductor device $Z_{\text {thjc }}$. This value is given by the manufacturer in the form of a graphic dependence of a family of characteristics at various duty cycles on the pulse time. Selection of the data values can simplify the calculation of the crystal temperature [8]:

$$
\mathrm{T}_{\mathrm{j}}(\mathrm{t})=\mathrm{T}_{\mathrm{c}}(\mathrm{t})+\mathrm{P}(\mathrm{t}) \cdot \mathrm{Z}_{\mathrm{thjc}}(\mathrm{t})
$$

where $\mathrm{P}=\mathrm{UI} \gamma$ and $\gamma$ is the duty cycle.

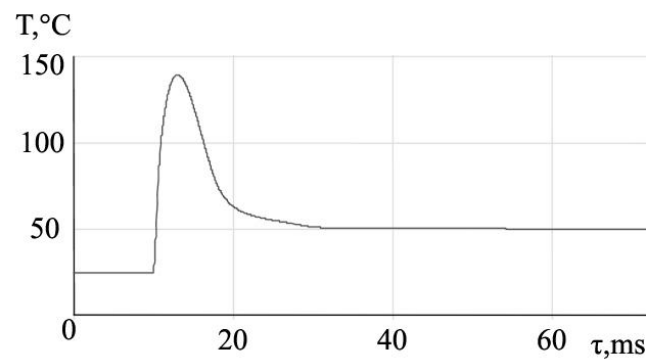

Fig. 2. A heat shock and a cooling of the transistor chip during the transition process

To simulate the active parameters of semiconductor devices, it is possible to represent them in the formula form. Thus, the author of [9] considers temperature dependence of the resistance of a drain-source transistor $R_{D S}$, direct resistance of a diode $\mathrm{R}_{\mathrm{VD}}$, and forward voltage of a diode $\mathrm{U}_{\mathrm{VD}}$ :

$$
\begin{aligned}
& \mathrm{R}_{\mathrm{DS}}=\mathrm{R}_{\mathrm{DS}_{0}} \cdot\left[\mathrm{T} \cdot \frac{1.024 \cdot \mathrm{U}_{\mathrm{DS}}^{0.1124}-1}{100}+\frac{5-1.024 \cdot \mathrm{U}_{\mathrm{DS}}^{0.1124}}{4}\right], \\
& \mathrm{R}_{\mathrm{VD}}=\mathrm{R}_{\mathrm{VD}_{0}} \cdot\left(1+\frac{\mathrm{T}-20}{298}\right), \\
& \mathrm{U}_{\mathrm{VD}}=\mathrm{U}_{\mathrm{VD}_{0}}-2 \cdot 10^{-3} \cdot(\mathrm{T}-20),
\end{aligned}
$$

where all zero values are reference data of the manufacturer.

During transients, the main objective when dealing with a system of differential equations is to analyse the first member of the matrix of coefficients, precisely the value of $r+\Delta r$. The other parameters during fast processes will not have time to heat up enough to significantly alter the electromagnetic parameters. However, by controlling the parameters of passive components, it is possible to change the nature of the transition process, thereby providing thermal protection of the system.

When semiconductor devices are heated, there is a decrease of the maximum current for operating at which the apparatus is designed. Due to the vibrational transition process at re-enabling a heated device, the maximum allowable value of the current can be exceeded, leading to the device failure.

By taking the data of the magnetic permeability of the inductor $\mathrm{L}$ at different temperatures, it can be seen that in the operating range from $0{ }^{\circ} \mathrm{C}$ to $70{ }^{\circ} \mathrm{C}$ the characteristic is almost linear and it can be described by a fairly linear relationship. To simulate the operation of the device in a wider operating temperature range, it is necessary to develop an equation that satisfies all of the functions. The best method is a regression analysis. The dependence of the magnetic permeability on temperature is represented as follows:

$$
\mu\left(\theta_{L}\right)=a_{n} \theta^{n}+a_{n-1} \theta^{n-1}+\ldots+a_{1} \theta+a_{0}=\Delta \mu\left(\theta_{L}\right)+\mu_{0} .
$$

When $\theta=\mathrm{T}-25^{\circ} \mathrm{C}$, the value of $\mathrm{a}_{0}$ is equal to the magnetic permeability of the material at a temperature of $25^{\circ} \mathrm{C}$. Fig. 3 shows a graphic representation of the dependence of the selected inductor: $\mu_{0}$ is the electromagnetic component of an electrothermal model, and $\Delta \mu$ - of a thermal model. The taken value was the polynomial degree $n=5$, since at this value the mean square error is sufficiently low, and the graph line passes through all given points with a deviation not exceeding $1 \%$. In the range from $-20{ }^{\circ} \mathrm{C}$ to $100{ }^{\circ} \mathrm{C}$, the points are spaced evenly, and above $100{ }^{\circ} \mathrm{C}$ the step is reduced.

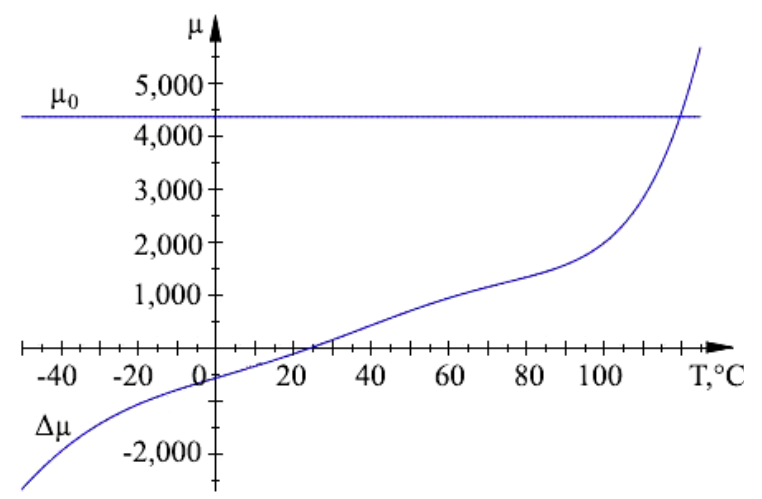

Fig. 3. The dependence of the electromagnetic and thermal components of the model of magnetic permeability on temperature

Losses in the active resistance and in the wire of the inductor are calculated by the formula with a known value of the root mean square current and the active resistance of the element:

$$
\mathrm{P}=\mathrm{I}_{\mathrm{rms}}^{2} \cdot \mathrm{R} \text {. }
$$

The loss in the magnetic circuit is calculated as:

$$
\mathrm{P}_{\text {magn }}=\frac{\mathrm{V}}{\mathrm{T}} \int_{0}^{\mathrm{T}} \mathrm{c}\left|\frac{\mathrm{dB}}{\mathrm{dt}}\right|^{\mathrm{x}}|\mathrm{B}(\mathrm{t})|^{\mathrm{y}-\mathrm{x}} \mathrm{dt},
$$

where $\mathrm{V}$ is the volume of the magnetic circuit; $\mathrm{c}, \mathrm{x}$, and $\mathrm{y}$ are the reference properties of the magnetic circuit, and $\mathrm{B}$ is the flux density [12].

In the case of the capacitor impedance simulation, the points' arrangement is of an exponential shape. With the exponential component, the characteristic begins to look like the original already at $\mathrm{n}=3$ :

$$
\mathrm{Z}=\mathrm{a}_{3} \mathrm{e}^{-\theta}+\mathrm{a}_{2} \theta^{2}+\mathrm{a}_{1} \theta+\mathrm{Z}_{0}
$$

At a frequency of $10 \mathrm{kHz}$, the response will appear as shown in Fig. 4. With this characteristic, it is possible to determine the dependence of the capacitance on temperature.

The power of the active losses in the capacitors can be found through the work of the reactive power on the loss tangent:

$$
\mathrm{P} \approx \mathrm{P}_{\text {react }} \cdot \operatorname{tg} \delta=2 \pi \mathrm{fU}^{2} \mathrm{C} \cdot \operatorname{tg} \delta .
$$

The reactive power of the capacitor must not exceed the permissible values specified by the manufacturer lest 
the condenser temperature at a given ambient temperature should exceed the maximum permissible value. The permissible value of the current through the capacitor depends on the permissible temperature of heating and the geometric dimensions of the housing, and it is provided in the technical documentation.

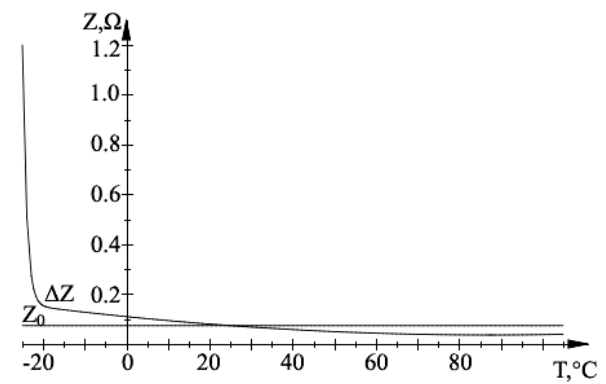

Fig. 4. Dependence of the electromagnetic and thermal components of the impedance model of the capacitor on temperature

\section{2. Differential equations of the system}

Let us devise differential equations of the open system. In general, the equation of the system state looks as follows:

$$
\frac{\mathrm{dX}}{\mathrm{dt}}=\mathrm{AX}+\mathrm{B}
$$

where $\mathrm{X}$ is a vector of state variables, $\mathrm{A}$ is a coefficient matrix, and $\mathrm{B}$ is a matrix of external influence.

For the step-down PWM converter that is shown in Fig. 1, the system looks as follows:

$$
\left|\begin{array}{c}
\frac{\mathrm{di}_{\mathrm{L}}}{\mathrm{dt}} \\
\frac{\mathrm{du}_{\mathrm{C}}}{\mathrm{dt}}
\end{array}\right|=\left|\begin{array}{cc}
-\frac{\mathrm{r}}{\mathrm{L}} & -\frac{1}{\mathrm{~L}} \\
\frac{1}{\mathrm{C}} & -\frac{1}{\mathrm{RC}}
\end{array}\right|\left|\begin{array}{l}
\mathrm{i}_{\mathrm{L}} \\
\mathrm{u}_{\mathrm{C}}
\end{array}\right|+\left|\begin{array}{c}
\frac{\mathrm{E} \cdot \mathrm{s}}{\mathrm{L}} \\
0
\end{array}\right|,
$$

where s corresponds to the state of the transistor. When the transistor is open, $\mathrm{s}=1$; when the transistor is closed, $\mathrm{s}=0$; $\mathrm{r}=\mathrm{r}_{\mathrm{VT}} \cdot \mathrm{s}+\mathrm{r}_{\mathrm{VD}} \cdot(1-\mathrm{s})+\mathrm{r}_{\mathrm{L}}$ is the sum of the resistances of the transistor, the diode and the inductor based of the transistor state; L, C, and R are the coil inductance, the capacitance of the capacitor and the load resistance, respectively, and $\mathrm{E}$ is the power supply voltage.

Let all the coefficients be equal to the values of the electric components of the parameters under normal conditions, excluding heating.

Since this system can be modified, then (9) takes the following form:

$$
\frac{d X}{d t}=\left(A_{e}+A_{t} \xi\right) X+B
$$

where $\mathrm{A}_{\mathrm{e}}$ is a component matrix corresponding to the operation of the device at a temperature of $25^{\circ} \mathrm{C}, \mathrm{A}_{\mathrm{t}}$ is a matrix of changes in the electrical parameter values of the components due to heating, and $\xi$ is a thermal coefficient matrix that is characterized by heat removal. At an ideal heat removal, the coefficient values are equal to zero, and the matrix of thermal coefficients stops affecting the system. If $\xi=1$, the heat is not removed, whereas at $\xi>1$ the device is heated up from the outside.

The matrix of variable coefficients for the circuit of a step-down PWM converter should include changing resistance of the transistor, diode and inductor $\Delta \mathrm{r}\left(\theta_{\mathrm{VT}}, \theta_{\mathrm{VD}}, \theta_{\mathrm{L}}\right)$, a change in the magnetic permeability of the inductor core, as well as the capacitance change $\Delta \mathrm{C}\left(\theta_{\mathrm{C}}\right)$, where $\theta=\mathrm{T}-25^{\circ} \mathrm{C}$ is a temperature of a particular component that differs from $25^{\circ} \mathrm{C}$.

The $\mathrm{A}_{\mathrm{e}}$ matrix is ill-conditioned, as it contains temperature-dependent components. Consequently, within one matrix, it is necessary to calculate both transients that last microseconds and thermal processes that last several hours. To simplify the calculations, the matrices are separated; in complex circuits of converters where it may be difficult to single out the models, it is possible to use the methods of diakoptics [13].

During steady operation modes, passive components set temperature regimes. In contrast to the intermittent operation mode, the semiconductor crystal temperature barely exceeds the device body temperature, which simplifies its adjusting with the help of the heat sink. Therefore, it is reasonable to consider steady operation modes while examining heating of passive components and considering that heating of semiconductor devices corresponds to a certain operational temperature point or changes periodically.

If the components are in close proximity to one another, they will have the same heating temperature, and the system will be much simpler. For example, at $\theta_{C}=\theta_{L}$, the value of the coefficient $\xi$ is the same for all components of the matrix except the first one. Assuming that for a steady operating mode of the system the semiconductor temperature is stable, without changes in a particular segment of work, this ratio will be a scalar number within $0 \leq \xi \leq 1$ in the absence of external heat sources.

The solution of the system of differential equations on the interval of an open transistor is the following:

$$
\left|\begin{array}{c}
\mathrm{I} \\
\mathrm{U}
\end{array}\right|=\mathrm{e}^{\mathrm{A} \gamma \mathrm{mT}}\left|\begin{array}{c}
\mathrm{I}(\mathrm{mT}) \\
\mathrm{U}(\mathrm{mT})
\end{array}\right|+\mathrm{A}^{-1}\left(\mathrm{e}^{\mathrm{A} \gamma \mathrm{m} T}-\mathrm{I}\right)\left|\begin{array}{l}
\frac{\mathrm{E}}{\mathrm{L}} \\
0
\end{array}\right| \text {, }
$$

where $A=A_{e}+\left.A_{t} \xi\right|_{s=1}, A^{-1}$ is an inverse matrix, and $I$ is an identity matrix.

In the period of a closed transistor, the solution takes the following form:

$$
\left|\begin{array}{c}
\mathrm{I} \\
\mathrm{U}
\end{array}\right|=\mathrm{e}^{\mathrm{A}(1-(1+\gamma) \mathrm{mT})} \cdot\left|\begin{array}{c}
\mathrm{I}(\mathrm{mT}+\gamma \mathrm{mT}) \\
\mathrm{U}(\mathrm{mT}+\gamma \mathrm{mT})
\end{array}\right|,
$$

where $A=A_{e}+\left.A_{t} \xi\right|_{s=0}$.

The nature of transient and steady processes is determined by the matrix exponential $\mathrm{e}^{\mathrm{At}}$, whose specific form is determined, in turn, by the eigenvalues $\lambda$ of the matrix A. The eigenvalues are found by the expression:

$$
\operatorname{det}(\mathrm{A}-\lambda \mathrm{I})=0 .
$$

Using the formulae of the matrix bisection on the basis of binary vectors [14], we have:

$$
\begin{aligned}
& \operatorname{det}\left(\mathrm{A}_{\mathrm{e}}+\xi \mathrm{A}_{\mathrm{t}}-\lambda \mathrm{I}\right)=\operatorname{det}\left(\mathrm{A}_{\mathrm{e}}-\lambda \mathrm{I}\right)+ \\
& +\sum(-1)^{\sigma} \Delta_{\mathrm{e}}\left(\mathrm{d}_{\mathrm{i}}\right) \xi \Delta_{\mathrm{t}}\left(\overline{\mathrm{d}_{\mathrm{i}}}\right)-\lambda^{2}+ \\
& +\operatorname{det}\left(\mathrm{A}_{\mathrm{t}}-\lambda \mathrm{I}\right)=0,
\end{aligned}
$$

where $\sigma$ is the sum of the column and row values of an element of the matrix, $\Delta_{\mathrm{e}}\left(\mathrm{d}_{\mathrm{i}}\right)$ is a minor that corresponds to the $\mathrm{d}_{\mathrm{I}}$ of the electromagnetic coefficients matrix, $\Delta_{\mathrm{t}}\left(\overline{\mathrm{d}_{\mathrm{i}}}\right)$ is a minor that corresponds to the complement of the binary vector $\overline{\mathrm{d}_{\mathrm{i}}}$ of the matrix of heating-based changes in the 
electromagnetic coefficients. This total in the unfolded form looks as follows:

$$
\begin{aligned}
& a_{11} \cdot \xi_{22} a_{22}(\theta)-a_{12} \cdot \xi_{21} a_{21}(\theta)- \\
& -a_{21} \cdot \xi_{12} a_{12}(\theta)+a_{22} \cdot \xi_{11} a_{11}(\theta) .
\end{aligned}
$$

On simplifying this equation for $\lambda$, we obtain the following quadratic equation:

$$
\lambda^{2}+b \cdot \lambda+c=0
$$

where $b=-a_{11}-a_{22}-\xi_{11} a_{11}(\theta)-\xi_{22} a_{22}(\theta)$, and $c$ is the sum of all available components of the equation.

The roots of the characteristic equation are defined as follows:

$$
\lambda_{1,2}=-\frac{1}{2}\left(\mathrm{~b} \pm \sqrt{\mathrm{b}^{2}-4 \mathrm{c}}\right) .
$$

If the roots are real, the transition process is aperiodic. This characteristic does not have current or voltage jumps, which is advantageous when switching on a heated device with reduced maximum allowable values of parameters of the semiconductor components. The temperature increase on the chip of the key elements will not be abrupt either, as shown in Fig. 2.

With complex roots, the quantity of the vibration component of the process depends on the proximity of the roots to the hypochondriac axis (Fig. 5).

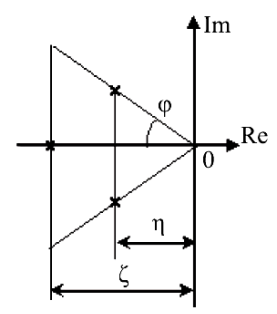

Fig. 5. The placement of the characteristic roots in the complex plane

The oscillation criterion is determined by the angle $\phi$ in the following way:

$$
\operatorname{tg} \phi=\frac{\operatorname{Im}(\lambda)}{\operatorname{Re}(\lambda)}
$$

where $\eta$ is the minimum value of the real root that determines the duration of the transition process as a value that is inversely proportional to the control time. The boundary $\zeta$, which is distant from the imaginary axis, is determined by the roots that have very little impact on the transition process.

According to Vieta's formulas, $b=\lambda_{1}+\lambda_{2}$, and $c=\lambda_{1} \lambda_{2}$. By introducing a value that is equal to the geometric mean of the roots of the equation $\Omega=\sqrt{\lambda_{1} \lambda_{2}}$, the characteristic equation can be written as follows:

$$
\lambda^{2}+\frac{\mathrm{b}}{\Omega} \cdot \Omega \cdot \lambda+\Omega^{2}=\lambda^{2}+\mathrm{B} \cdot \Omega \cdot \lambda+\Omega^{2}=0
$$

In this form, the value B characterizes the curve of the transition process, and $\Omega$ is the scale of the process time $\tau=\Omega \cdot$.

With the equation in this form, it is possible to ensure thermal protection of the device at the methodological level, during transients in the design of the device, or during the realization of the circuit beyond the stationary mode, or while carrying out feedback on the temperature and gradually stabilizing the operation of the converter. For example, in the intermittent mode, during the oscillatory transient process, the current peaks are higher than the limit value of the key parameters. Hereby, it is essential to choose properly the core of the inductor so that it, at a certain frequency and intensity of the magnetic field during the heating, could change the inductance of the throttle as much as to decrease the vibrational component. Thus, the roots of the characteristic equation are moving away from the imaginary axis, the value $\mathrm{B}$ is reduced, but $\Omega$ on the contrary increases. The nature of the transients is close to aperiodic, and the process duration increases.

\section{Thermal converter protection management}

As a result of the aforementioned calculations, it is possible to create thermal protection of a converter both during transition processes by managing the degree of the process oscillation and during steady-state operation. The nature of the transition process can be directly influenced just by changing the intensity of the magnetic field of the coil, for example, by introducing a parallel DC-controlled coil and thus changing the angle $\phi$. It is also possible to choose the magnetic material of the core so that the heating will increase the inductance of the coil and the amplitude of the transient will decline to a safe level, which is necessary for heated semiconductor devices with lowered boundary values of the parameters (Fig. 6).
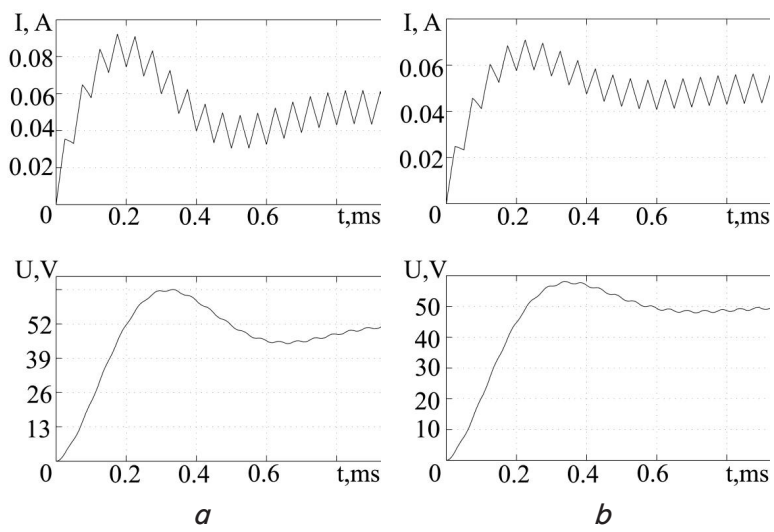

Fig. 6. A transient within a step-down PWM converter at the following parameters: $a-$ the inductor temperature is $25^{\circ} \mathrm{C}$; $b$ - the inductor temperature is $90^{\circ} \mathrm{C}$

These results show that even by properly choosing the material of the core of the inductor it is possible to protect the converter from overheating. By controlling the intensity of the magnetic field of the inductor, the nature of the transition process can be changed from oscillatory to aperiodic. An aperiodic nature of the process is the safest option in the case of a recloser with heated semiconductor devices.

\section{The use of electrosimulation for thermal protection}

This approach can be used in the theoretical calculations for electric processes and for modelling systems that require high precision. For example, for adjusting the transition process characteristics, it is possible to create a thermal 
protection system that operates like a feedback chain on temperature (Fig. 7).

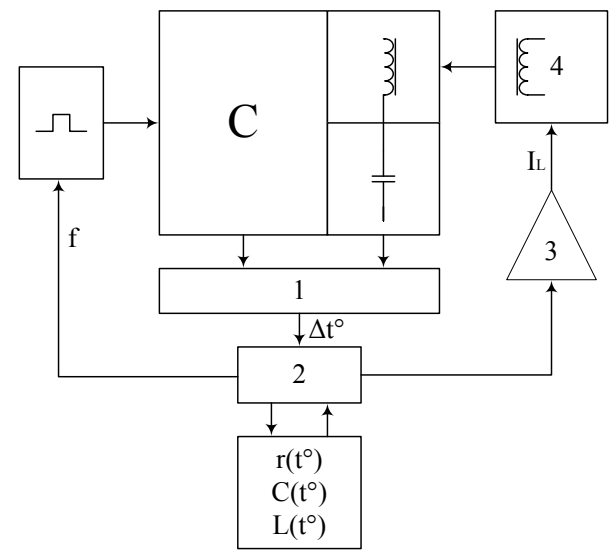

Fig. 7. A thermal protection system for a pulse converter

$\mathrm{C}$ in Fig. 7 is a pulse converter whose switch receives switch-on and switch-off pulses of a specific frequency that is set by the generator or a chain of command. The converter circuit contains an LC filter, as in the above described second order step-down PWM. The converter components have thermal sensors (1) that transmit the temperature value of the device elements to the microprocessor (2) with an incorporated thermal model of all the elements. The next steps include: recalculation of the electromagnetic values of the elements' parameters, analysis of the complexity of the transition process on determining the temperature by the temperature sensors, and stabilization of the processes by changing the input frequency of switching on the converter switch, thereby affecting the reactance value of the inductors and circuit capacitors. At the same time, adjustment can be made through the operational amplifier (3) by changing the DC that powers the inductor (4) that is connected with the magnetic transducer of the filter coil, thereby changing the magnetic field intensity and thus the thermal characteristics of the magnetic permeability of the core.

The dependence of the magnetic permeability on the temperature at low magnetic field intensity means an increase of the magnetic permeability as the heating increases to the $\mathrm{Cu}$ rie temperature and then sharply declines after reaching this temperature. As the magnetic field intensity increases, this dependence begins to grow at a slower rate; on reaching the predetermined value of tenseness, this dependence changes into the opposite direction, which means that the magnetic permeability decreases while temperature increases. It is possible to control this feature to stabilize the electromagnetic processes as to temperatures that are critical for the circuit or to change the nature of the transition process by increasing its time and turning the oscillation process into aperiodic.

\section{Discussion of the results of using the electrothermal modelling to create thermal protection of pulse converters}

A combined electrothermal modelling is necessary to ensure thermal protection of devices. There are many techniques and simulation packages of both electromagnetic transducer processes and separate thermal processes. For example, when modelling transients of a pulse transmitter in computer environments (e.g., Simulink or Plecs), it is possible to connect components that are responsible for heat transfer and heat capacity. However, these applications will not take into account that, as a result of changes due to heat or hot restart of the device, the inductor will receive a modified current, and hence the intensity of the magnetic field of the coil will be different from the one specified by the user. Consequently, the dependence of the magnetic permeability on the magnetic core temperature will be different. A similar problem may arise in relation to other elements. The advantage of this method is that, while analysing the electromagnetic and thermal processes, these nuances are taken into account and the calculation will be more accurate, which will expand the boundaries of safe operation of converters.

This method is useful when calculating devices that work in conditions bordering on the maximum modes. This method is also relevant to ensure heat protection of semiconductor devices during transients when the thermal protection devices as well as the cooling system can not prevent thermal shock in the crystal of semiconductor devices due to the brevity of the cooling process and the inertia of the heat capacity of the elements. The procedure can be used to create additional thermal protection systems by choosing materials of the device elements so that during their heating either the transient oscillations will diminish or the transition process will change its character.

The present study is a ground for further creation of thermal protection systems, soft-start systems of pulse converters, and control systems for electric stabilization processes in pulse converters.

\section{Conclusions}

1. To solve the problem of a combined electrothermal modelling, the study suggests equations of the system state with addition of a thermal component and heat transfer characteristics. Thermal and electrical components of the equations were singled out due to poor conditioning of the coefficient matrix; while solving the differential equation, the integration time for calculating electromagnetic and thermal processes is different.

2. The example of a step-down PWM converter provides solutions to the equations of state. The nature of the transition process in these solutions depends on the matrix exponentials. The position of the characteristic roots of the matrix in the complex plane characterizes the nature of the transition process. The closer are the roots to the real axis, the smaller is the oscillation in the process. If the roots are not complex, the transition process is aperiodic, which is the most secure form that should be aimed at when switching on a heated device. Vieta's formulas can help select parameters of the circuit elements so as to obtain the desired form of electromagnetic processes at different temperatures.

3. By using this technique for electrothermal process modelling, it is possible to choose the elements of the converter circuit. For example, in a step-down PWM converter with a selected magnetic material of the inductor core for high permeability dependence on heating, the transient oscillations at high temperatures will be smoothed, thereby making the reclosing of the device safer for the key semiconductor elements. An additional chain of thermal protection on a microprocessor with a programmed electrothermal model can be created to serve as feedback on temperature or to work as a system of soft start-up when the device is re-enabled. 


\section{References}

1. Fabis, P. M. Thermal modelling of diamond-based power electronics package [Text] / P. M. Fabis, D. Shun, H. Windischmann // Fifteenth Annual IEEE Semiconductor Thermal Measurement and Management Symposium, 1999. - P. 98-104. doi: 10.1109/ stherm.1999.762434

2. Du, B. Transient Electrothermal Simulation of Power Semiconductor Devices [Text] / B. Du, J. Hudgins, E. Santi, A. Bryant, P. Palmer, H. Mantooth // IEEE Transactions on Power Electronics. - 2010. - Vol. 25, Issue 1. - P. 237-248. doi: 10.1109/ tpel.2009.2029105

3. Leuca, T. Using Some Coupled Numerical Models in Problems of Designing an Inductive Electrothermal Equipment [Text] / M. Novac, B. Stanciu, A. Burca, M. Codrean // Journal of Electrical and Electronics Engineering. - 2014. - Vol. 7, Issue 1. P. $77-80$.

4. Drofenik, U. A general scheme for calculating switching-and conduction-losses of power semiconductors in numerical circuit simulations of power electronic systems [Text] / U. Drofenik, J. W. Kolar // International Power Electronics Conference (IPEC'05), 2005.

5. Drofenik, U. Computationally efficient integration of complex thermal multi-chip power module models into circuit simulators [Text] / U. Drofenik, D. Cotet, A. Musing, J. M. Meyer, J. W. Kolar // 2007 Power Conversion Conference - Nagoya, 2007. P. 550-557. doi: 10.1109/pccon.2007.373020

6. Merrikh, A. A. Compact thermal modeling methodology for predicting skin temperature of passively cooled devices [Text] / A. A. Merrikh // Applied Thermal Engineering. - 2015. - Vol. 85. - P. 287-296. doi: 10.1016/j.applthermaleng.2015.04.007

7. Divins, D. Using Simulation to Estimate MOSFET Junction Temperature in a Circuit Application [Text] / D. Divins // International Rectifier, Power Electronics Technology Exhibition \& Conference, 2007. - P. 27.

8. Schutze, T. Thermal equivalent circuit models [Text] / T. Schutze // Germany: Infineon Technologies AG, 2008. - P. 10.

9. Malyna, D. Accelerated synthesis of electrically and thermally constrained power electronic converter systems [Text] / D. Malina. Eindhoven, Eindhoven University Press, 2007. - 229 p.

10. Soft Ferrites. Data Handbook MA01, Philips Components [Text]. - Netherlands: Philips Electronics, 1996. - 887 p.

11. Aluminium Electrolytic Capacitors [Text]. - Germany: Epcos AG, 2014. - 40 p.

12. Pressman, A. Switching Power Supply Design [Text] / A. Pressman. - New York: McGraw-Hill, Inc., 1998. - 807 p.

13. Kron, G. Diakoptics, The Piecewise Solution of Large Scale Systems [Text] / G. Kron. - London: MacDonald \& Co. 1963.

14. Filaretov, V. V. Teorema Sigorskogo ob opredelitele summy matric i diakoptika [Text] / V. V. Filaretov // Electronics and communications. - 2010. - Vol. 2. - P. 5-13. 